\title{
Perancangan Desain 3D Modelling Sebagai Media Ilustrasi Pada CV. Pacific Alumunium
}

\author{
Muhammad Faisal ${ }^{1}$, Wiranti Sri Utami ${ }^{2}$, Ruli Supriati ${ }^{3}$ \\ 1,2,3 Program Studi Teknik Informatika, Fakultas Sains dan Teknologi, Universitas Raharja \\ e-mail: ${ }^{\text {11 }} \underline{\text { muhammad.faisal@ raharja.info, }},{ }^{2}$ wiranti.utami@ raharja.info, ${ }^{3}$ ruli@ raharja.info
}

\begin{abstract}
Abstrak
Desain merupakan sebuah gambaran ilustrasi untuk mencapai suatu tujuan untuk menunjang daya tarik konsumen dalam meningkatkan penjualan. CV. Pacific Alumunium merupakan badan usaha yang bergerak dibidang jasa penjualan alumunium yang mengerjakan pembuatan konstruksi seperti kitchen set, partisi kaca, outlet, dll. Masalah yang di alami oleh pihak CV. Pacific Alumunium adalah belum tersedianya media ilustrasi misalnya desain 3D sebagai gambaran untuk menyesuaikan keinginan dari klien. Oleh sebab itu dibutuhkan suatu perancangan desain 3D dengan menggunakan Metode Multimedia Development Life Cycle (MDLC).Tujuan dari penelitian ini adalah Menghasilkan suatu media ilustrasi dalam bentuk desain 3D modelling, sehingga keinginan konsumen dapat tercapai melalui visualisasi desain $3 D$.
\end{abstract}

Kata Kunci - Desain 3D, Ilustrasi, MDLC

\begin{abstract}
Design is an illustration to achieve a goal to support consumer attraction in increasing sales. CV. Pacific Aluminum is a business entity engaged in aluminum sales services that carry out construction work such as kitchen sets, glass partitions, outlets, etc. The problem experienced by the CV. Pacific Alumunium is the unavailability of illustration media, such as $3 D$ designs as an illustration to match the wishes of clients. Therefore, a $3 D$ design is needed using the Multimedia Development Life Cycle (MDLC) method. The purpose of this research is to produce an illustration media in the form of $3 D$ designs. modeling, so that consumer desires can be achieved through $3 D$ design visualization.
\end{abstract}

Keywords - Design 3D, Illustration, MDLC

\section{PENDAHULUAN}

Perkembangan teknologi sangat mempengaruhi dalam hal penyampaian informasi dan komunikasi pada media cetak maupun elektronik. Salah satu media yang memanfaatkan perkembangan teknologi ini adalah media cetak yang bertujuan untuk menyampaikan informasi dan promosi tentang instansi atau perusahaan yang membuka jasa pembuatan produk dengan memanfaatkan desain ilustrasi yang berbentuk 3D modelling.

Desain 3D modeling digunakan untuk membuat sebuah gambaran atau ilustrasi untuk menuangkan ide atau gagasan yang ingin dicapai sebelum masuk ke dalam tahap pengembangan. Dengan adanya desain 3D maka konsep desain akan lebih mudah dimengerti dan dipahami sesuai kebutuhan dan keinginan. Contoh penerapan desain 3D adalah di bidang konstruksi.

Pembuatan desain 3D sangat bermanfaat karena dapat memberikan gambaran kepada klien terhadap hasil yang akan dicapai pada tahap perancangan produk. Pembuatan desain 3D adalah hal yang tepat sebagai media ilustrasi, karena dapat menyajikan ide dan konsep sehingga produk yang akan dihasilkan nanti dapat sesuai dengan keinginan klien.

Dengan adanya proses pembuatan ilustrasi desain 3D modelling yang akan penulis lakukan pada CV. Pacifi Alumunium membuat konsep desain kitchen set yang diinginkan oleh 
klien dengan memperhatikan hal-hal seperti pemilihan material, ukuran, pemilihan warna, dan juga melakukan konsultasi kepada klien mengenai desain bentuk desain yang di inginkan. Hal ini perlu dilakukan guna memberikan gambaran kepada klien mengenai hasil akhir yang akan di capai.

Sedangkan CV. Pacific Alumunium belum memiliki desain ilustrasi dalam bentuk 3D modelling. Selama ini desain ilustrasi masih menggunakan sketsa kasar sebagai media penyampaian informasi terhadap klien. Oleh sebab itu dengan adanya desain ilustrasi 3D modelling, ilustrasi dalam bentuk desain 3D akan lebih mudah dipahami karena di visualisasikan dalam bentuk real melalui tahapan yang dinamakan render desain 3D.

Tujuan dilakukannya penelitian ini adalah untuk membantu pihak dari CV. Pacific Alumunium dalam menjelaskan konsep desain yang akan dibuat kepada klien menggunakan desain ilustrasi 3D modelling.

Untuk mendukung proses penelitian ini penulis menggunakan sebuah software khusus dalam proses perancangan desain 3D Modelling. Software yang digunakan adalah software yang dikembangkan oleh perusahaan Autodesk yaitu 3DS Max. Dan sebagai pelengkap dari hasil proses pembuatan desain 3D Modelling agar gambar 3D menjadi lebih real penulis menggunakan plugin V-ray, V-ray merupakan perangkat lunak yang dikembangkan oleh Chaos Group.

\section{METODE PENELITIAN}

Untuk mendukung proses penelitian ini maka penulis menggunakan beberapa metode antara lain : (1) Studi Pustaka, yaitu dengan menggunakan referensi terhadap jurnal yang berkaitan dengan penelitian ini. (2) Observasi, dengan melakukan survey langsung ke salah satu klien dari CV. Pacific Alumunium. (3) Research and Development sebagai dasar prosedur yang dikembangkan oleh Luther pada tahun 1994 atau yang lebih dikenal dengan proses Multimedia Development Life Cycle (MDLC). Menurut Luther dalam Binanto ${ }^{[1]}$ " Multimedia Development Life Cycle (MDLC) terdiri dari 6 tahapan, yaitu Concept, Design, Material Collecting, Assembly, Testing dan Distribution.

Penelitian yang dibuat oleh Agustinus dkk, (2015) ${ }^{[2] ~ " D e s a i n ~ I n t e r i o r ~ R u m a h ~ d e n g a n ~}$ 3DS Max untuk Keperluan Pembuatan Video Image di Masterpiece Studio". Menjelaskan tentang perusahaan yang bergerak dibidang arsitektural rendering yang mengalami banyaknya permintaan proses pembuatan gambar 3D dan disertai dengan animasi, dalam hal ini klien meminta proses pembuatan animasi dilakukan dengan cepat padahal proses tersebut akan memakan waktu yang relatif lama. Oleh sebab itu perusahaan menggunakan video image sebagai proses pembuatan animasi karena memakan waktu yang lebih cepat, metode yang digunakan pada penelitian ini adalah kualitatif deskriptif.

Selanjutnya penelitian yang dilakukan oleh Baskoro dkk, (2021) ${ }^{[3]}$ "Rekonstruksi Interior Bangunan Sejarah Optik Surya Dengan Model 3D". Menjelaskan tentang rekonstruksi sebuah bangunan bersejarah menggunakan 3D Interior dengan melakukan analisa desain dan prinsip desain guna mengetahui ciri khas bangunan tersebut, proses penelitian ini menggunakan metode kualitatif deskriptif.

Penelitian yang dilakukan oleh Bima Putra Blesilla, Joko Samudro, Arif Sutrisno, $(2021)^{[4]}$ "Perancangan Desain Asset dan Environment Game 3D "Road To Campus". Peneltian ini bertujuan untuk membuat suatu game dalam bentuk 3D, dimana pemain berinteraksi dalam konflik permainan yang sudah disepakati dan didalam permainan terdapat peraturan yang bertujuan membatasi perilaku pemain dan menentukan targer yang ingin dicapai. Metode perancangan menggunakan metode Agile, merupakan metode perancangan menajeman perangkat lunak.

Penelitian yang dilakukan oleh Benny Rahmawan Noviadji, Angga Hendrawan, $(2021)^{[5]}$ "Perancangan Buku Ilustrasi Sebagai Media Pengenalan Bidang Keilmuan Desain". Menjelaskan tentang purwarupa buku dengan pendekatan ilustrasi untuk memberikan motivasi 
belajar dan pemahaman bagi siswa SMA, metode yang digunakan pada penelitian ini adalah Research and Development dengan pendekatan model ADDIE.

Penelitian yang dilakukan oleh Siti Hardini, Yanuar Rahman, $(2018)^{[6]}$ "Perancangan

Buku Ilustrasi Kesehatan Untuk Wanita Karir". Menjelaskan tentang proses perancangan buku ilustrasi kesehatan untuk menerapkan pola hidup sehat kepada masyarakat khususnya kepada wanita, konten yang dibuat disesuaikan agar dapat menyampaikan pola hidup sehat dengan menyenangkan, metode yang digunakan adalah observasi, studi pustaka, dan wawancara serta kuesioner.

Penelitian yang dilakukan oleh Yosepin Sri Ningsih, Jeani Widjaja, (2021) ${ }^{[7]}$ " Perancangan Ilustrasi Koleksi Busana Dengan Karakter Visual Tenun Tradisional Indonesia". Proses perancangan ilustrasi kain tenun tradisional untuk kebutuhan dunia fashion dan lifestyle, dengan menggunakan metode kualitatif dan penyebaran kuesioner.

Selanjutnya penelitian yang dilakukan oleh Randa Januario Pratama, I Nyoman Miyarta Yasa, (2020) ${ }^{[8]}$ "Perancangan Buku Ilustrasi Sebagai Media Informasi Tentang Stres". Perancangan buku ilustrasi yang membahas tentang informasi stres dengan membuat konsep sesederhana mungkin dan semenarik mungkin agar mudah dipahami oleh anak remaja, metode yang digunakan pada penelitian ini menggunakan design thinking yang berguna untuk memecahkan masalah yang tepat dalam sebuah karya.

Berikutnya penulis akan menjelaskan metode Research and Development sebagai dasar prosedur yang dikembangkan oleh Luther-Sutopo yaitu Multimedia Development Life Cycle (MDLC). Langkah-langkah dan proses tersebut dapat dilihat pada gambar dibawah ini:

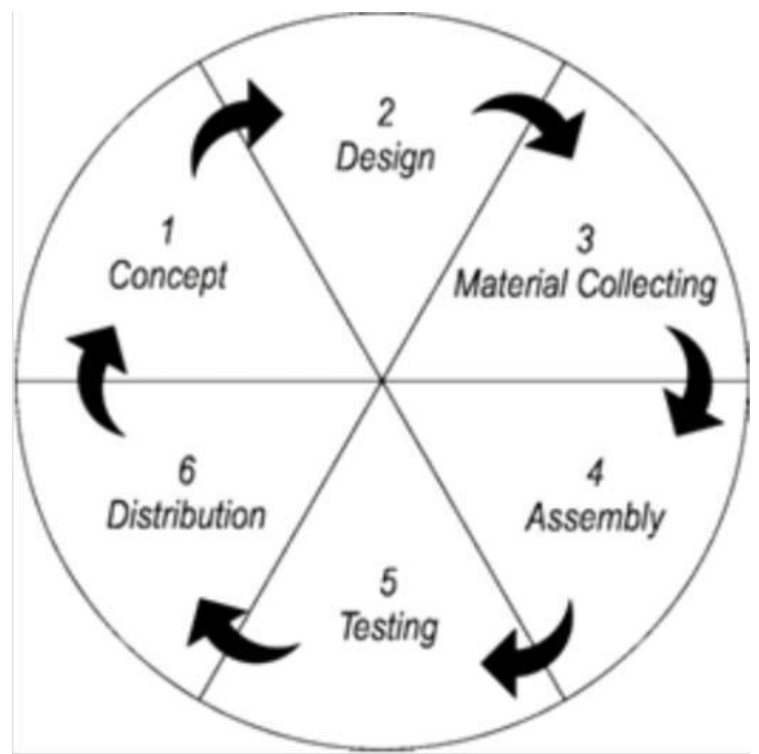

Gambar 1. Multimedia Development Life Cycle

Berikut ini merupakan tahapan dari Multimedia Development Life Cycle :

a. Concept

Tahapan Concept (Konsep) merupakan tahapan tujuan untuk menentukan desain ilustrasi 3D. Selain itu untuk mengumpulkan ide-ide desain yang akan buat model 3D.

b. Design

Design merupakan tahapan perancangan dan pembuatan model 3D pada perangkat lunak 3DS Max, tahapan ini akan menentukan bahan-bahan yang akan digunakan untuk proses pembuatan produk real nya.

c. Material Collection

Tahapan ini merupakan tahapan menentukan material dan bahan yang akan digunakan sesuai dengan permintaan klien. Bahan-bahan tersebut antara lain Jenis kayu, Lapisan finishing, Lighting, dan lain-lain. 
d. Assembly

Tahapan perancangan desain ilustrasi 3d modelling terbagi menjadi 2 tahapan antara lain, (1) tahapan pembuatan model 3D kitchen set dan (2) perancangan desain interior ruangan. pada setiap perancangan akan melalui proses pemberian tekstur material.

e. $\quad$ Testing

Setelah semua tahapan sudah dilalui maka proses selanjutnya adalah melakukan tahapan testing, tahapan ini dinamakan dengan proses render. Proses render adalah membuat gambar 3D pada aplikasi 3DS Max menjadi lebih real dengan menggunakan plugin $\mathrm{V}$ Ray.

\section{f. Distribution}

Pada tahapan akhir ini hasil dari proses rendering akan disimpan kedalam format JPG dalam bentuk gambar.

\section{HASIL DAN PEMBAHASAN}

Proses pembuatan desain 3D modelling Kitchen Set mengikuti tahapan yang ada pada metode MDLC. Proses tersebut dapat dilakukan secara paralel atau tidak berurutan namun proses concept dan design harus dilakukan pada tahapan awal.

\section{a. Concept (Konsep)}

Tahapan Concept (Konsep) merupakan tahapan tujuan untuk menentukan desain ilustrasi 3D. Selain itu untuk mengumpulkan ide-ide dan pembuatan sketsa kasar, hal ini dilakukan untuk mempermudah penulis dalam melakukan pembuatan model 3D pada aplikasi 3DS Max.

\section{b. Design (Desain)}

Proses yang dilakukan pada tahapan ini adalah menentukan jenis produk desain yang akan dibuat sesuai dengan permintaan klien. Jenis produk yang akan dibuat pada penelitian ini adalah Kitchen Set. Pada proses ini penulis melakukan konsultasi kepada klien dan juga membuat sketsa kasar untuk menentukan model dan tata letak desain yang akan dibangun. Selanjutnya penulisan membuat tampilan Kitchen Set, sebagai gambaran kasar model Kitchen Set yang akan dibuat.

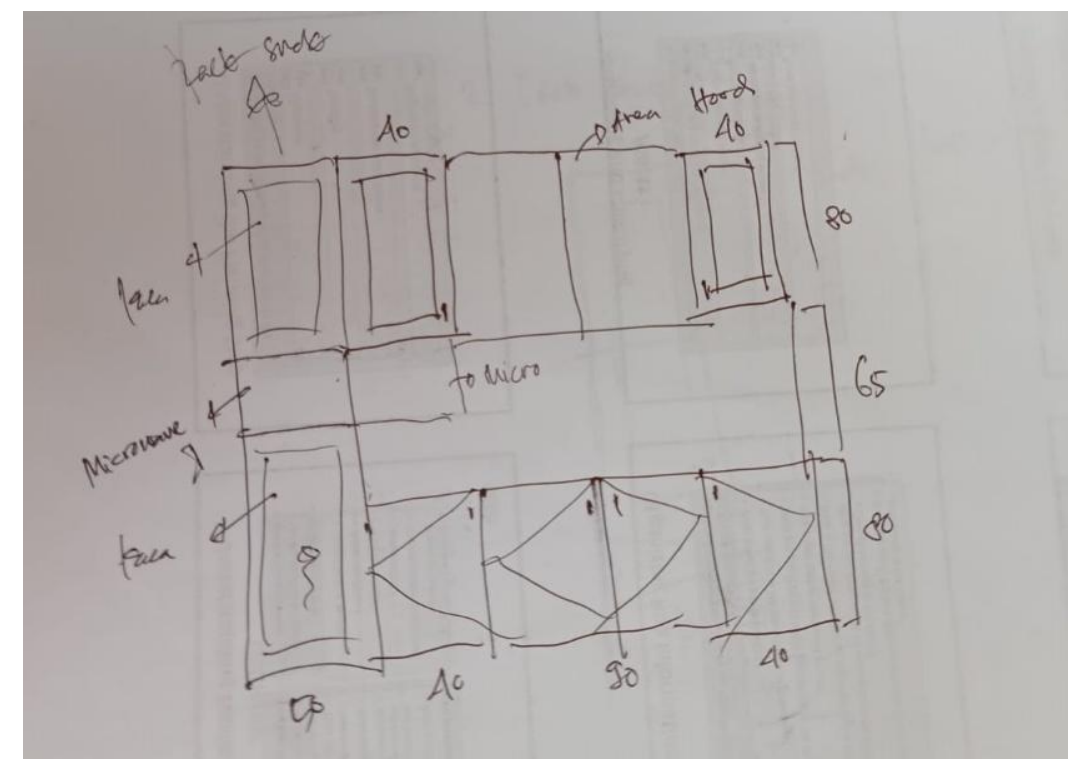

Gambar 2. Sketsa Kasar tampak depan (Kitchen Set) 


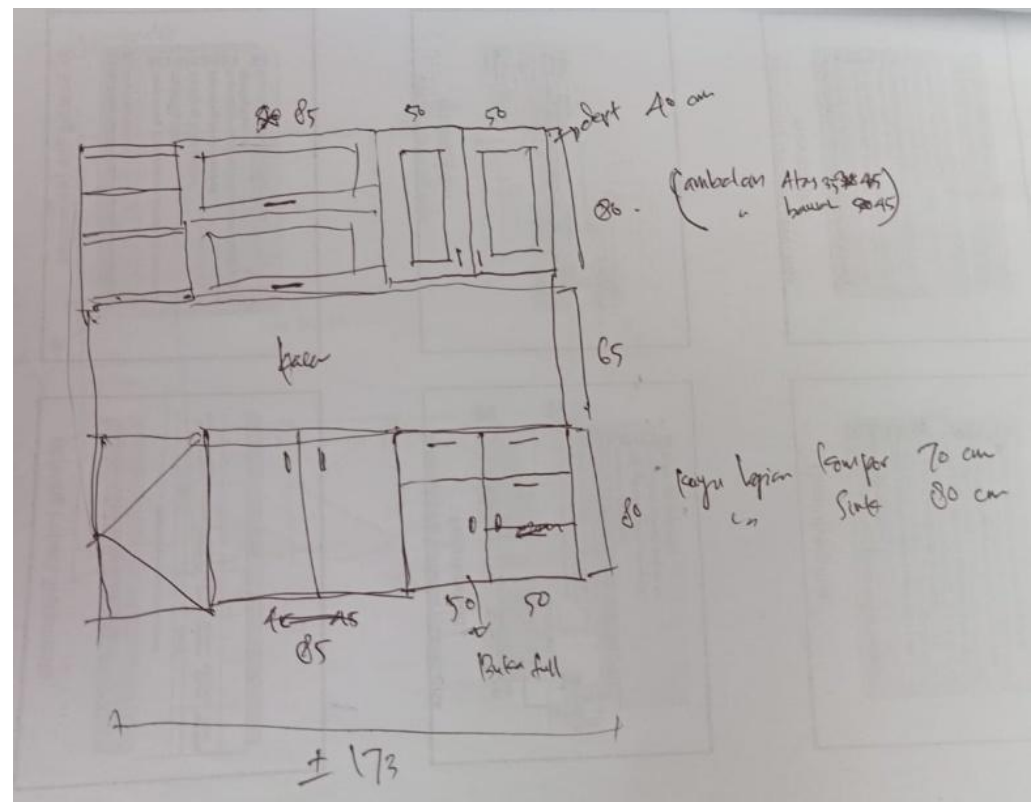

Gambar 3. Sketsa Kasar tampak samping (Kitchen Set)

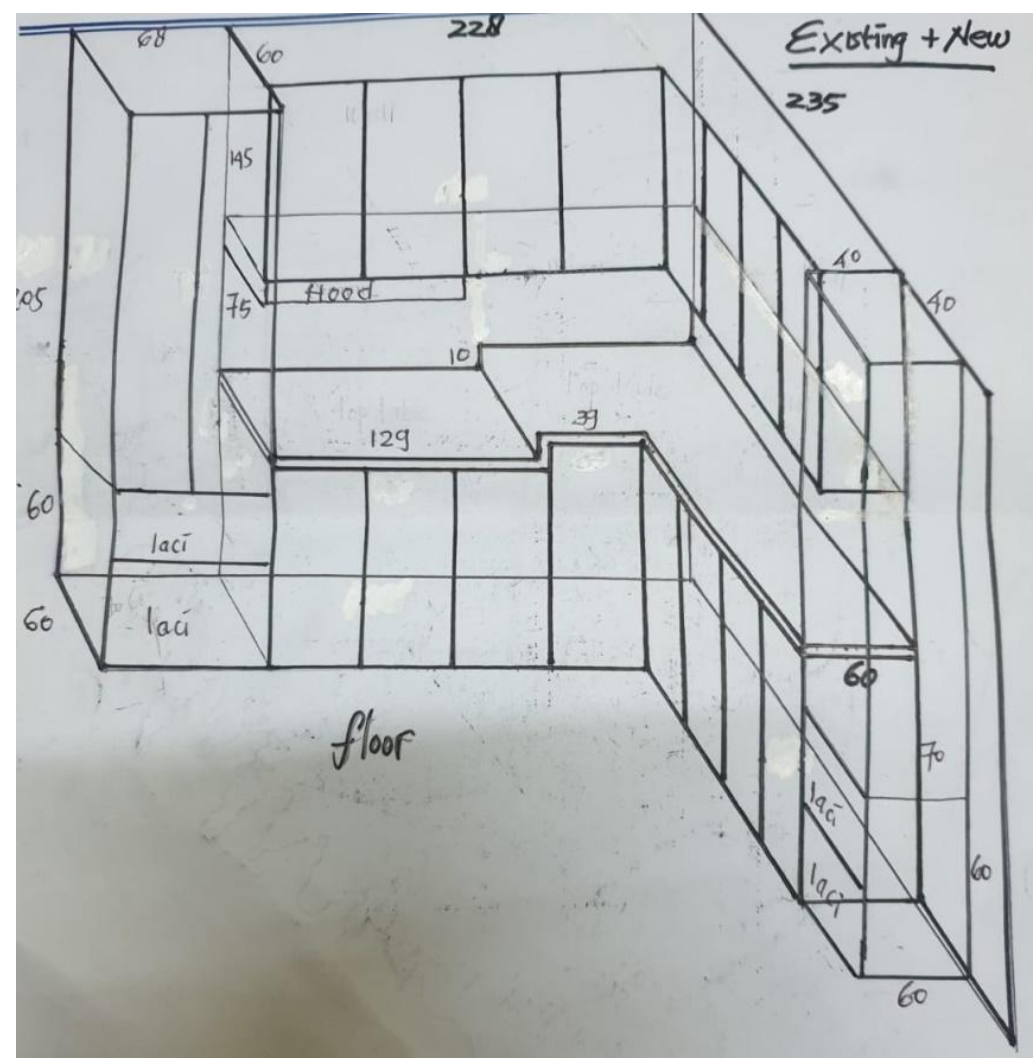

Gambar 4. Sketsa Kasar tampak perspektif (Kitchen Set) 
Print ISSN: 2723-1992

Online ISSN: 2723-200X

Tahapan ini merupakan tahapan menentukan material dan bahan yang akan digunakan sesuai dengan permintaan klien. Berikut ini merupakan tabel lampiran material yang akan digunakan.

Tabel 1. Daftar Material

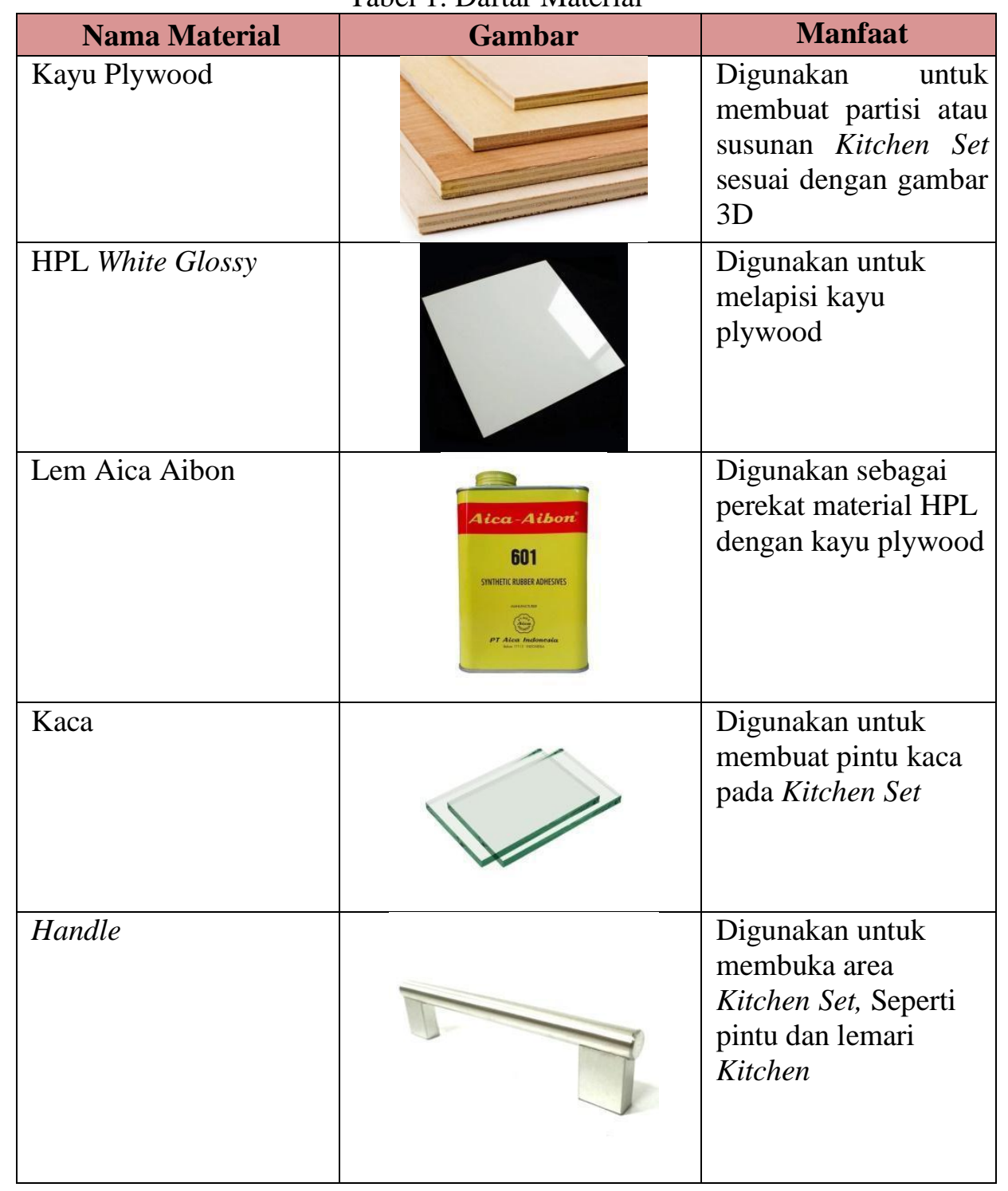


d. Assembly

Tahapan perancangan desain ilustrasi 3d modelling pembuatan model 3D kitchen set terbagi menjadi dua bagian. Proses pertama membuat desain 3D modelling dan proses kedua setelah proses 3D selesai masuk kedalam proses Pemberian warna atau Material Collection sesuai dengan daftar material yang digunakan.

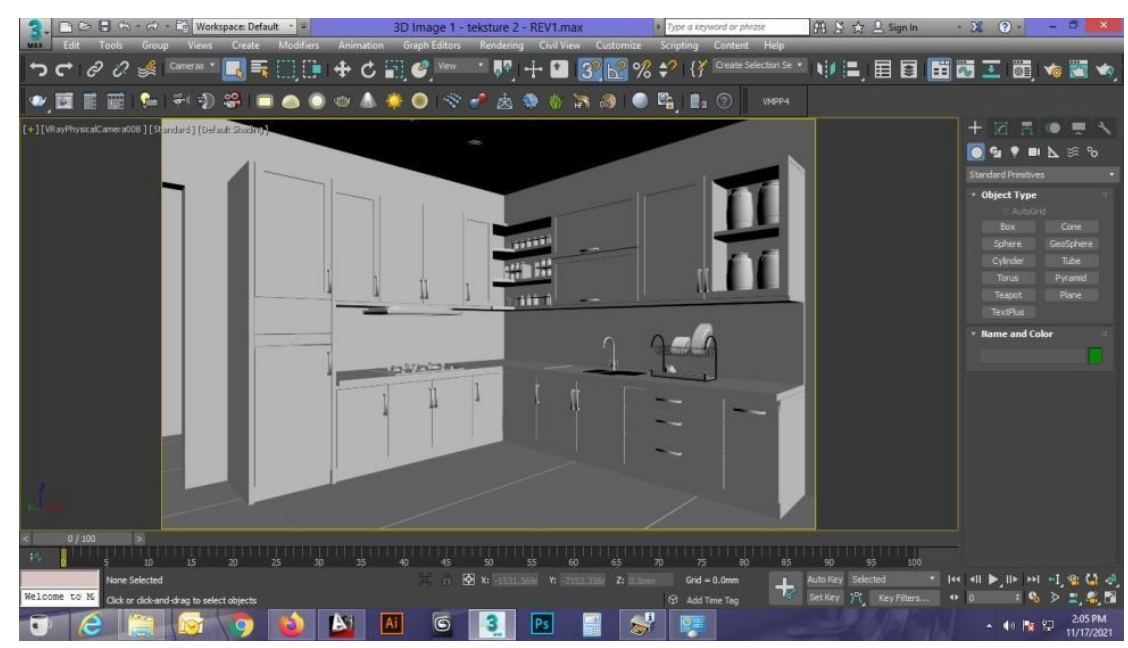

Gambar 5. Model 3D Kitchen Set

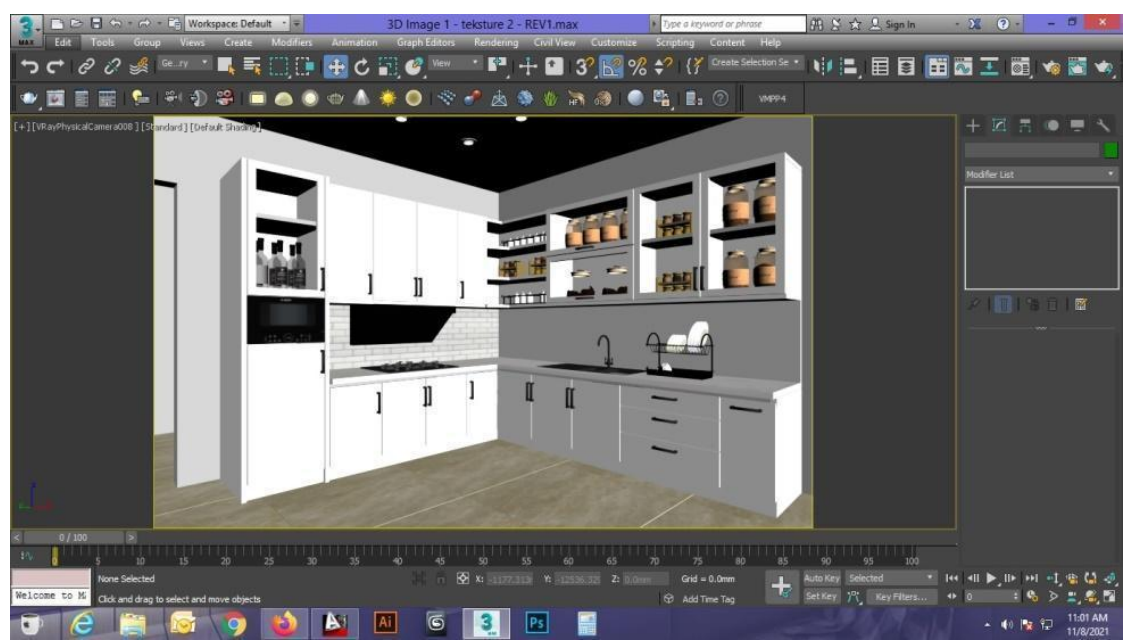

Gambar 6. Model 3D Kitchen Set dan Pemberian Warna

(Material Collection) 


\section{e. Testing}

Setelah semua tahapan sudah dilalui maka proses selanjutnya adalah melakukan tahapan testing, tahapan ini dinamakan dengan proses render. Proses render adalah membuat gambar 3D pada aplikasi 3DS Max menjadi lebih real dengan menggunakan plugin V-Ray. Proses ini akan memakan waktu yang cukup lama dan membutuhkan specs komputer yang tinggi guna menghasilkan gambar lebih real atau nyata.

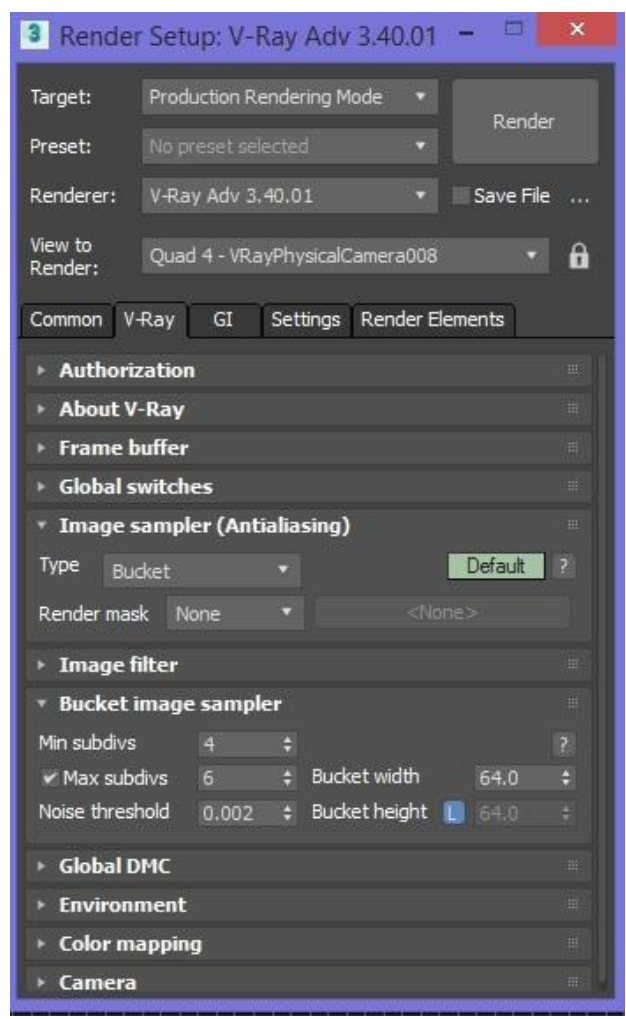

Gambar 7. Jendela Plugin V-ray

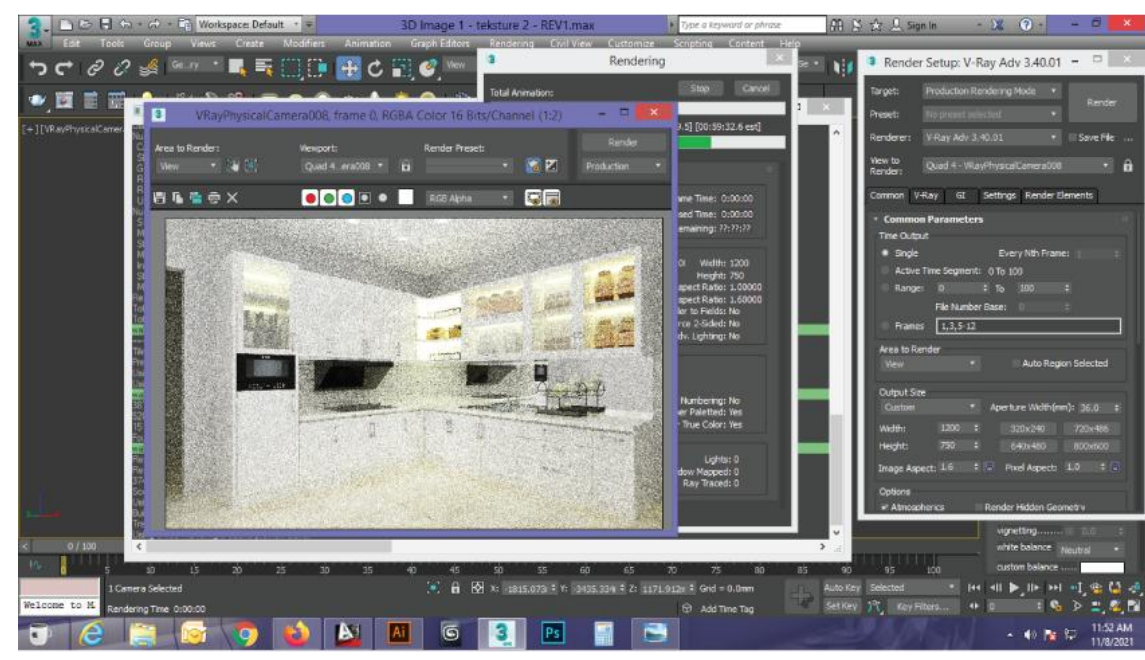

Gambar 8. Proses Render V-Ray 


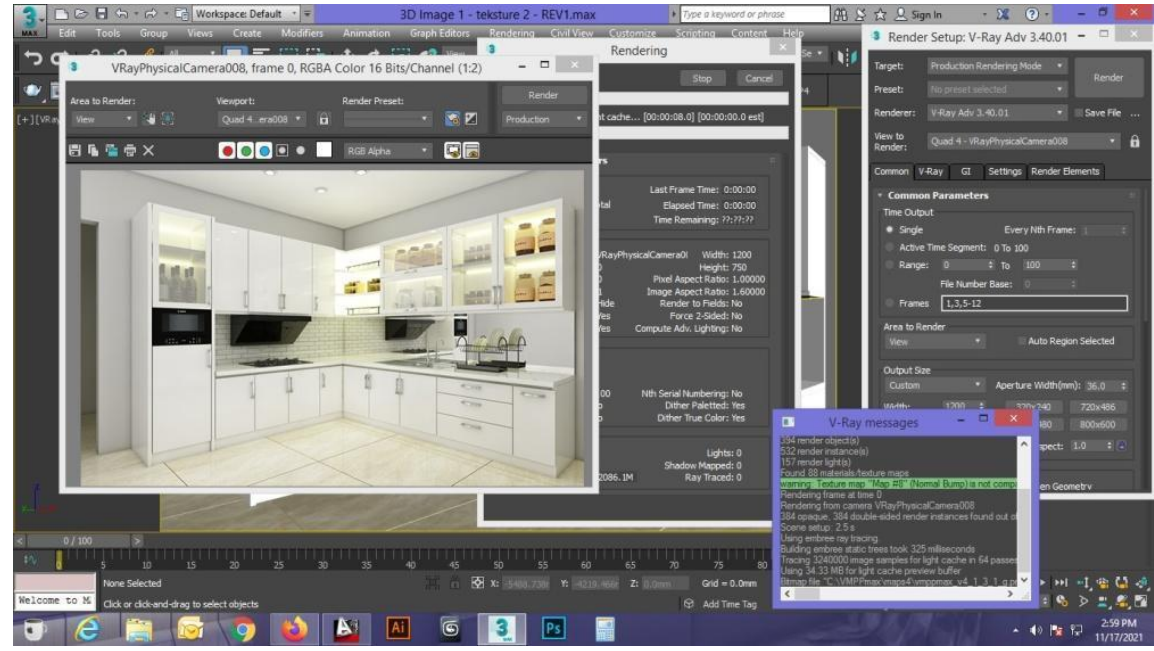

Gambar 9. Hasil Render V-Ray

\section{f. Distribution}

Pada tahapan akhir ini hasil dari proses rendering akan disimpan kedalam format JPG dalam bentuk gambar. Hasil dari proses rendering ini akan memberikan kesan gambar menjadi lebih real. Diharapkan proses ini dapat memberikan kesan yang menarik terhadap klien yang akan dihasilkan setelah masuk kedalam proses produksi.

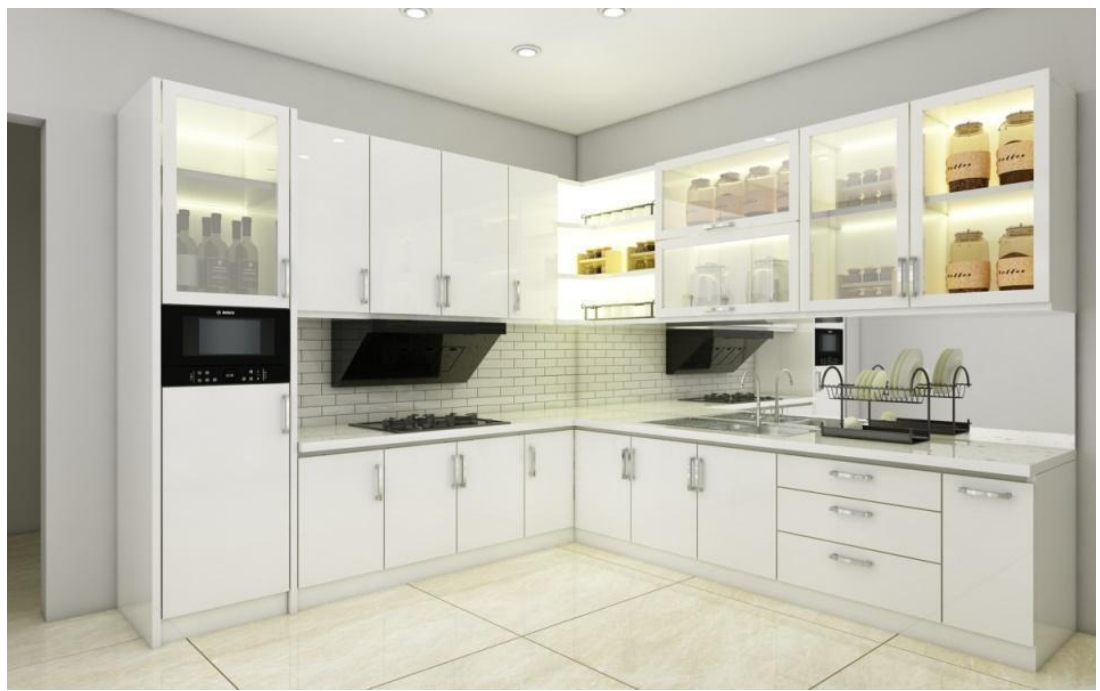

Gambar 10. Proses Hasil Render V-Ray

\section{KESIMPULAN}

Berdasarkan hasil dari proses perancangan dan tahapan yang telah dilalui kesimpulan yang dapat diambil dari proses perancangan model 3D ilustrasi ini adalah :

Pembuatan desain ilustrasi 3D modeling dapat menyelesaikan masalah yang sedang dialami oleh CV. Pacific Alumunium sebagai media penyampaian ilustrasi model kitchen set yang akan dibuat sesuai dengan kebutuhan atau keinginan dari klien, sehingga permasalahan yang ada di lapangan dapat terhindari dengan adanya proses pembuatan desain ilustrasi 3D modelling.

Setelah semua proses dan tahapan sudah dilalui maka akan masuk kedalam proses produksi. Proses ini akan menghasilkan suatu produk Kitchen Set yang akan dibuat oleh CV. Pacific Alumunium berdasarkan hasil dari pemodelan ilustrasi gambar 3D yang telah dibuat. 
Dalam hal ini penulis menyesuaikan dengan keinginan klien CV. Pacifi Alumunium, dari hal pembuatan konsep awal, tata letak, dan material yang akan digunakan.

\section{SARAN}

Dari hasil perancangan model ilustrasi 3D pada CV. Pacific Alumunium, Dalam hal melakukan proses pembuatan produk jadi di lapangan dapat menghasilkan produk yang sesuai dengan gambar ilustrasi 3D yang sudah dibuat. Seperti memperhatikan tampilan bentuk, warna atau material, serta ukuran agar sesuai dengan kondisi dilapangan.

\section{DAFTAR PUSTAKA}

[1] I. Binanto., 2010, Multimedia Digital Dasar Teori Pengembangannya. Yogyakarta: CV. Andi Offset.

[2] Sirumapea, Agustinus, Budi Setiawan, dan Rian Sujana, 2015, Desain Interior Rumah dengan 3DS Max untuk Keperluan Pembuatan Video Image di Masterpiece Studio. Jurnal Sisfotek Global. Vol. 5 No. 2: 67-71, Tangerang: STMIK Global

[3] Azis, Baskoro, Adisti Safrilia, dan Ida Bagus Ananta Wijaya, 2021, Rekonstruksi Interior Bangunan Sejarah Optik Surya Dengan Model 3d. Mintakat: Jurnal Arsitektur. Vol. 22 No. 2: 76-87, Malang: Universitas Merdeka Malang

[4] Putra Blessilla, Bima, Joko Samodra, dan Arif Sutrisno, 2021, Perancangan Desain Asset dan Environment Game 3D "Road to Campus". Journal of Language, Literature. Vol. 1 No. 9: 1171-1187, Malang: Universitas Negeri Malang

[5] Noviadji, Benny Rahmawan, dan Angga Hendrawan, 2021, Perancangan Buku Ilustrasi Sebagai Media Pengenalan Bidang Keilmuan Desain. Jurnal Desain. Vol. 8 No. 2: 103-121, Surabaya: Institut Informatika Indonesia (IKADO)

[6] Hardini, Siti, dan Yanuar Rahman, 2018, Perancangan Buku Kesehatan Untuk Wanita Karir. Jurnal Komunikasi Visual dan Multimedia. Jurnal Andharupa. Vol. 4 No. 01: 42-50, Semarang: Universitas Dian Nuswantoro

[7] Sri Ningsih, Yosepin, dan Jeani Widjaja, 2021, Perancangan Ilustrasi Koleksi Busana Dengan Karakter Visual Tenun Tradisional Indonesia. Jurnal Dimensi Seni Rupa dan Desain. Vol. 17 No. 2: 117-136, Jakarta: Universitas Trisakti

[8] Januario Pratama, Randa, dan I Nyoman Miyarta Yasa.,2020, Perancangan Buku Ilustrasi Sebagai Media Informasi Tentang Stres. Jurnal Sasak Desain Visual dan Komunikasi. Vol 2. No. 2: 59-66 Mataram: Universitas Bumigora 